\title{
Ensino de geometria: uma experiência com crianças surdas
}

\section{Teaching geometry: an experiment with deaf kids}

\author{
Renata da Silva Dessbese \\ Universidade Tecnológica Federal do Paraná - UTFPR - Ponta Grossa - Brasil \\ renatadessbesel@utfpr.edu.br \\ Cristiano Couto do Amarante \\ Universidade Tecnológica Federal do Paraná - UTFPR - Ponta Grossa - Brasil \\ criscoutodoamarante@gmail.com \\ Sani de Carvalho Rutz da Silva \\ Universidade Tecnológica Federal do Paraná - UTFPR - Ponta Grossa - Brasil \\ sani@utfpr.edu.br \\ Elsa Midori Shimazaki \\ Universidade Estadual de Maringá - UEM - Maringá - Brasil \\ emshimazaki@uem.br
}

\section{Resumo}

Este estudo tem como objetivo realizar um relato de experiência com o uso de estratégias visuais e contextualizadas para o ensino de geometria com crianças surdas em uma escola bilíngue. Fundamentados na teoria Histórico-Cultural, utilizaram-se de materiais manipuláveis que permitem à matemática tornar-se visual, de modo que as crianças possam se apropriar dos conceitos mediante 0 uso de materiais que possibilitam a elaboração de estratégias fundamentais em sua educação. A atividade é caracterizada com uma abordagem qualitativa. Participaram da pesquisa alunos surdos que frequentam - Ensino Fundamental da escola bilíngue, a professora regente de matemática, assim como a coordenadora pedagógica e a pesquisadora. Inferiu-se que a diversidade de materiais utilizados junto aos alunos surdos, aliada à mediação do conhecimento por meio de instrumentos e da língua de sinais, proporcionou aos estudantes um ambiente rico para a consolidação do processo de ensino e aprendizagem dos conceitos de geometria.

Palavras-chave: educação de surdos, ensino de matemática, geometria.

\section{Abstract}

This paper aims to conduct an experience report, using visual and contextualized strategies to teach geometry to deaf kids from a bilingual school. Based on the CulturalHistorical Theory, manipulable supplies were used to allow the Mathematics becomes visible, enabling the kids to understand the concepts through materials that allow to elaborate essential strategies in education. The activity is featured with a qualitative approach. Deaf students participated in the research, who attend the Elementary School in a bilingual institution, as well the Mathematics responsible teacher, the coordinator and the researcher. The supplies diversity used with the deaf students, associated to knowledge measure through instruments and the sign language, provided to the students an 
environment to consolidate the geometry concepts teaching-learning process.

Keywords: deaf education, teaching mathematics, geometry.

\section{Introdução}

A interface ensino de matemática e educação da pessoa surda tem trazido inquietações e consequentemente discussões entre os professores e pesquisadores, uma vez que o ensino mediado pela língua de sinais e recursos visuais ainda é desconhecido por muitos profissionais. Nesta pesquisa, apresentou-se o ensino de geometria direcionado ao uso de materiais manipuláveis que auxiliem no processo de aprendizagem (ARNOLDO JR.; RAMOS; THOMA, 2013) de crianças surdas e na ampliação do vocabulário da Língua Brasileira de Sinais (Libras) com relação aos sinais para geometria (SALES; PENTEADO; MOURA, 2015). A esse respeito, Peixoto e Lopes (2016) afirmam que as experiências visuais associadas à instrução em língua de sinais são fundamentais no processo de ensino e aprendizagem de matemática, uma vez que contemplam a língua materna dos estudantes surdos e a valorização da sua cultura.

A Libras é reconhecida como meio de comunicação e expressão pela Lei 10.436 , de 24 de abril de 2002, a qual posteriormente foi regulamentada pelo Decreto 5.626, de 22 de dezembro de 2005. O reconhecimento da Libras como língua oficial ajuda no acesso dos surdos a um ensino de qualidade, com respeito a sua língua materna. No entanto, ainda são necessários muitos avanços para a consolidação do espaço de educação em uma perspectiva bilíngue e que reconheça a cultura surda.

A língua de sinais atua como um signo mediador utilizado para estabelecer a comunicação entre os surdos com as pessoas ouvintes. Seu uso favorece o desenvolvimento das habilidades cognitivas e linguísticas, pois como pontua Vygotsky (1997), a surdez não traz barreiras cognitivas ao surdo, mas sim a falta de acesso às relações sociais por meio de uma língua. Vygotski (1997) sinaliza que na educação das crianças surdas, do ponto de vista psicológico e pedagógico, é o mesmo que nas crianças ouvintes: a diferença reside na substituição da forma de comunicação, cuja base são as relações sociais.

À medida que as crianças surdas se desenvolvem, é imprescindível um ambiente rico e estimulador para o desenvolvimento da linguagem, espaço em que a língua de sinais seja a primeira língua, para que a partir da aquisição, elas organizem seus pensamentos e decidam sobre as ações para com o mundo externo (MOURA, 2013). Nesse sentido, Santana, Muniz e Peixoto (2018) pontuam a necessidade de as crianças surdas vivenciarem o compartilhamento linguístico, porque o contato e a socialização por meio da Libras permitem que a língua seja adquirida em diferentes interações: "o sujeito surdo é membro de uma comunidade surda de minoria linguística que tem uma cultura própria, caracterizada pela sua experiência visual e linguística" (SANTANA; MUNIZ; PEIXOTO, 2018, p.120).

Destaca-se que as relações sociais, internas ou externas à sala de aula, mediadas pela língua de sinais, contribuem para o desenvolvimento de conceitos básicos da matemática (KRITZER; PAGLIARO, 2013). Soares e Sales (2018) afirmam que a comunicação em Libras permite aos surdos compreender as situações que os rodeiam e organizem seus conceitos referentes ao mundo. Silva (2010, p. 223) declara que "oportunizar situações que favoreçam a ação da criança no e com os objetos do meio ambiente, intermediadas por sua língua natural".

Defende-se que a educação das crianças surdas necessita de meios para a compensação da linguagem oral, ou seja, alterar a conexão com as relações sociais por outro canal de comunicação (VYGOTSKI, 1997). A língua de sinais cumpre a função da comunicação, e como aponta Góes (2012), o bilinguismo como forma de orientação 
educacional assume a língua de sinais como primeira língua, que deve ser ensinada ainda na fase de desenvolvimento inicial da criança.

No ensino e aprendizagem de matemática, estão presentes, além da linguagem expositiva, o uso de instrumentos de mediação para a resolução das atividades propostas. $\mathrm{Na}$ educação dos surdos, os gestos também são ferramentas importantes para a compreensão dos conceitos. Healy e Ferreira Santos (2014) alegam que as expressões corporais são elementos importantes nas estratégias utilizadas pelos alunos surdos. Dessa forma, ao apresentar os conteúdos em sala de aula, deve-se enfatizar as características que a língua de sinais possui, de modo que sejam explorados os aspectos visuais com o uso dos braços e pernas, as expressões faciais e corporais (LACERDA; SANTOS; CAETANO, 2013).

A negociação e o compartilhamento de sinais permitem o envolvimento dos alunos e se tornam parte da resolução das situações propostas (HEALY; FERREIRA SANTOS, 2014). No desenvolvimento da aula de matemática, os sinais construídos e compartilhados pelos alunos ajudam no processo de aprendizagem e contribuem para a sua interação (SALES; PENTEADO; MOURA, 2015).

O uso de materiais manipuláveis permite que a matemática se torne mais visual, e que se possa explorar o algoritmo e a explicação oral, permitindo que os alunos manipulem materiais, observem as próprias ações dos colegas e em parceria com 0 professor construam estratégias. Soares e Sales (2018, p. 81) afirmam que como elemento motivador em sala de aula está o reconhecimento das capacidades sensoriais visuais: "os recursos visuais facilitam a aprendizagem, ficando evidente que a dinâmica das aulas de Matemática é o que compromete a aprendizagem". A inserção de jogos nos momentos de aprendizagem contribui para despertar o interesse e envolver os alunos na construção dos conhecimentos, como assegura Grando (2004); os jogos apresentam entre suas vantagens a ressignificação dos conceitos, a participação ativa do aluno, 0 desenvolvimento da criatividade, a interação social e o trabalho em grupo.

Nesse cenário, discorre-se sobre o ensino de geometria repleto de possibilidades, tais como a conexão com os outros campos da matemática, a exploração de situações do cotidiano e de uma matemática visual. O desenvolvimento de conteúdos de geometria considera a experimentação de situações reais, de modo que os alunos visualizem, desenhem e relacionem as situações apresentadas em contextos reais (LEMOS; KAIBER, 2018).

A Base Nacional Comum Curricular (BNCC) (BRASIL, 2017), documento orientador para a Educação Básica, assim aborda o ensino de geometria e o desenvolvimento do pensamento geométrico: "esse pensamento é necessário para investigar propriedades, fazer conjecturas e produzir argumentos geométricos convincentes" (BRASIL, 2017, p. 271). Atividades que oportunizem a manipulação, a visualização, a construção, as comparações e escolha de estratégias de análise e resolução favorecem as relações entre o aluno e o conteúdo de matemática (LEMOS; KAIBER, 2018).

O planejamento dos momentos de aprendizagem consiste na elaboração de situações problema que contemplem o letramento matemático, nas quais o aluno seja capaz de realizar leituras e escritas em matemática, compreenda e argumente sobre as questões propostas (VISMARA, 2015). O letramento matemático, considerado em um processo mais amplo, se refere às práticas de interação com a sociedade, como, por exemplo, abordar os conteúdos em sala de aula a partir de atividades em que se explore textos de circulação nas mídias (COUTINHO; CARVALHO, 2016). De acordo com a BNCC (BRASIL, 2017), a matemática no ensino fundamental deve compreender o desenvolvimento do letramento matemático, no sentido de que os alunos percebam as aplicações dos conteúdos e como esses interagem com o mundo.

Diante do exposto, neste estudo tem como objetivo realizar um relato de experiência com o uso de estratégias visuais e contextualizadas para o ensino de 
geometria com crianças surdas em uma escola bilíngue.

\section{Metodologia}

A atividade relatada neste artigo realizou-se em dois encontros de 90 minutos cada, no segundo semestre de 2018, em uma escola bilíngue de educação de surdos localizada em um município no Estado do Paraná.

Os participantes foram alunos surdos do ensino fundamental, com idades compreendidas entre sete e onze anos, além da participação da professora de matemática e tradutora e intérprete de Libras, da coordenadora pedagógica e da pesquisadora. Ao todo, participaram 15 alunos surdos. Os encontros foram planejados e propostos a partir do tema e conteúdos sugeridos pela professora da escola. A atividade realizada é resultado da parceria entre a escola e a universidade, com o objetivo de trocar experiências e proporcionar momentos de ensino e aprendizagem para todos os envolvidos (professores, intérpretes, alunos e pesquisadores).

Como recursos, foram utilizados materiais manipuláveis, jogos e multimídia, e os dois encontros aconteceram na escola. As atividades foram registradas em diário de campo da pesquisadora e em tarefas realizadas pelos alunos, coletadas ao final dos encontros. $\mathrm{Na}$ próxima sessão explicitou-se o desenvolvimento das atividades e as discussões relativas ao ensino de geometria.

\section{Resultados e discussões}

O processo de ensino e aprendizagem dos alunos surdos perpassa pela atenção às especificidades de sua comunicação, de forma que se estabeleçam relações com 0 meio externo e que a sala de aula constitua um espaço de trocas visando a se tornar um ambiente de ensino e aprendizagem (LACERDA; SANTOS; CAETANO, 2013). A temática escolhida no desenvolvimento dos encontros foi a Copa do Mundo de 2018, que estava acontecendo no momento da intervenção pedagógica, com a escola decorada para os jogos e os alunos entusiasmados com as questões que envolviam o futebol. Após o planejamento com a equipe da escola e a produção do material, estipulou-se os dias dos encontros e foi feito o convite aos alunos para participarem.

No primeiro encontro, participaram apenas três alunos, motivado pela forte chuva em que as crianças não conseguiram ir à escola. Propuseram-se três atividades, a primeira um diálogo sobre formas geométricas planas, a segunda sobre sólidos geométricos e a terceira sobre a construção dos sólidos com uso de material manipulável. Com o tema "Copa do Mundo 2018 e a Geometria" projetou-se na tela do multimídia imagens como bola, campo de futebol, bandeira da Rússia e a Catedral São Basílio. Após ocorreu um diálogo em Libras sobre cada uma das figuras, de modo que cada aluno relatasse o que conhecia das imagens e dos sinais correspondentes.

Foram selecionadas as figuras que possuíam semelhanças com formas geométricas, introduziu-se o estudo das figuras planas, seu sinal em Libras, suas características e relação com outros objetos. De acordo com as orientações da BNCC (BRASIL, 2017), entre as habilidades para serem desenvolvidas no contexto da geometria está reconhecer e comparar figuras planas e compreender a relação entre os lados e vértices. Após o reconhecimento das figuras geométricas planas, convidou-se os alunos para, a partir de um material concreto (peças de E.V.A), montar as bandeiras das 32 seleções de futebol participantes da Copa do Mundo de 2018, como mostra a Figura 1. 
Figura 1: Registro das bandeiras que os alunos montaram

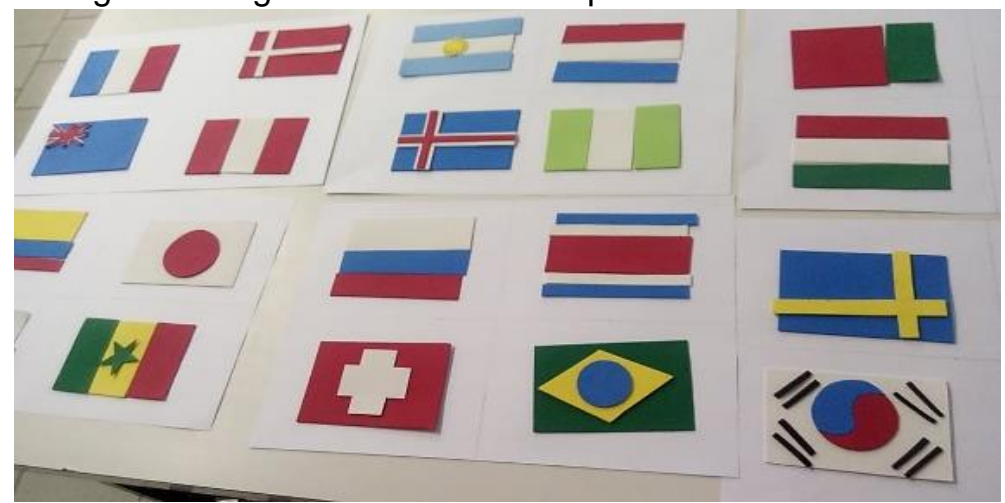

Fonte: Pesquisa de Campo (2018)

Os alunos montaram as bandeiras com muito entusiasmo e durante essa atividade comentaram sobre os jogos do Brasil e compartilharam sinais em Libras de alguns países que tinham aprendido com os professores da escola. Essa atividade oportunizou aos estudantes o papel ativo na produção do conhecimento. Soares e Sales (2018) apontam que a exploração de recursos visuais é potencializadora do ensino e aprendizagem de matemática e atua também como motivadora nesse processo. Durante o diálogo ${ }^{1} \mathrm{com}$ as crianças destacou-se as formas geométricas que formavam as bandeiras, como apresentado no Quadro 1.

Quadro 1: Diálogo sobre a bandeira do Brasil

Pesquisadora: Quais formas geométricas é possível observar
na bandeira do Brasil?
Aluno 12: Eu sei. Retângulo.
Pesquisadora: Muito bem Aluno 1. Qual mais?
Aluno 2: Um círculo azul.
Pesquisadora: Muito bem Aluno 2. E esta figura amarela? Qual
o nome?

Fonte: Pesquisa de campo (2018)

Os alunos não se lembravam do nome da figura amarela, explicou-se que essa forma geométrica é chamada losango; apresentou-se o sinal em libras e algumas características dessa forma. A negociação de sinais em Libras para as figuras geométricas apresentadas constituiu uma oportunidade de interação e reconhecimento dos conhecimentos que os alunos trouxeram para sala de aula, e estes se sentiram motivados a compartilhar os sinais. Durante os diálogos, observou-se que haviam retângulos de diferentes tamanhos nas bandeiras, ainda que em algumas bandeiras as figuras usadas fossem iguais, que só mudavam as cores ou a posição. A utilização de materiais nesse momento permitiu a manipulação dos objetos e a visualização aproximou os alunos dos conhecimentos sobre geometria. Sales, Penteado e Moura (2015) argumentam que a associação de ilustrações, diagramas e informações escritas são significativas para a aprendizagem dos alunos surdos.

A próxima atividade foi proposta a partir do reconhecimento de formas no espaço, e com o auxílio dos sólidos geométricos ensinou-se seus conceitos e características. Foram mostrados aos alunos os sinais em Libras de cada sólido (cubo, pirâmide, paralelepípedo, cone e o cilindro), alguns já eram conhecidos destes. Após a manipulação dos objetos e diálogo sobre as características dessas formas, propôs-se aos estudantes que, com o uso de varetas e massa de modelar, confeccionassem os sólidos. Nessa construção os alunos

\footnotetext{
1 Os diálogos aconteceram em Libras.

2 Por questões éticas, os nomes dos alunos foram substituídos por nomes fictícios.
} 
mostraram muita desenvoltura e criatividade, ajudaram os colegas e constataram que é preciso certa quantidade de massa de modelar para que os sólidos ficassem estáveis sobre a mesa.

O segundo encontro ocorreu na semana seguinte: os alunos estavam ansiosos para mostrarem à pesquisadora as novas formas geométricas que haviam construído, como também novas curiosidades sobre a Copa do Mundo de 2018. Nesse encontro estavam presentes 15 estudantes e a divisão das atividades foi proposta em dois momentos: no primeiro com o plano cartesiano e no segundo um jogo de Batalha Geométrica.

Para a apresentação do Plano Cartesiano, utilizou-se do aparelho multimídia para projetar na tela a imagem do plano (Figura 2) e algumas bandeiras de países em diferentes locais desse plano. Indagou-se aos alunos onde se encontravam as bandeiras, ou seja, qual a coordenada de cada bandeira. No entanto, esta não era conhecida por eles, então foi necessária a mediação em Libras sobre o eixo das abscissas, o eixo das ordenadas, as coordenadas e o ponto em que estavam situadas as imagens, como ilustra esse trecho do diálogo do Quadro 2.

Figura 2: Atividade do plano cartesiano

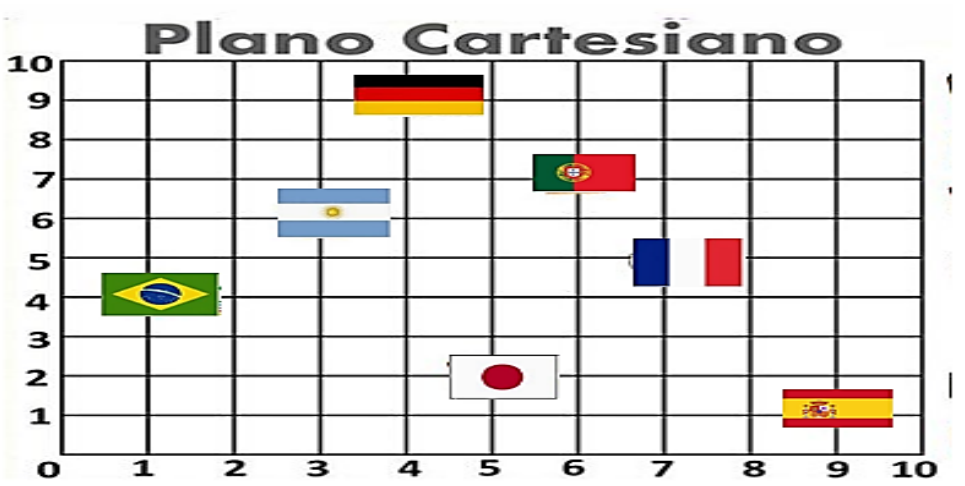

Fonte: Pesquisa de campo (2018)

Quadro 2: Diálogo sobre o plano cartesiano

Pesquisadora: Olhem para a bandeira do Brasil no plano cartesiano. Certo! Onde ela está? Em qual ponto?

Professora de matemática: Olhem o plano cartesiano, temos os números na horizontal (por exemplo, 1,2,3,4...) e os números na vertical. Agora em que número está a bandeira do Brasil?

Aluno 4: Eu sei! 5!

Pesquisadora: 5? Explica para nós por quê 5?

Aluno 4: É assim, 1 embaixo e 4 na lateral, então 5.

Professora de matemática: Ok! Mas vamos retomar, um ponto é formado por duas coordenadas, um número que está na horizontal (eixo abscissas) e encontra um outro número na vertical (eixo das coordenadas). Na bandeira do Brasil, temos 1 embaixo e encontra com o 4 na lateral. Assim, a bandeira está localizada no ponto (1 e 4). Entenderam?

Aluno 1: Entendi. A bandeira da Alemanha é 3 e 6 ! 
Fonte: Pesquisa de campo (2018)

No diálogo do Quadro 2, verifica-se que alguns conceitos não eram do conhecimento dos alunos e foi preciso a nossa intervenção, com exemplos, para a compreensão. O auxílio da professora de matemática foi fundamental ao fazer uso da imagem e em língua de sinais fazer a explicação, usando também gestos que complementavam a explicação. Healy e Ferreria Santos (2014) realçam a importância dos gestos e expressões visuais que contribuem para a compreensão dos estudantes nas tarefas de matemática.

Salienta-se que a explicação do enunciado em Libras não é suficiente para a compreensão da atividade, como expõem Nogueira, Andrade e Zanqueta (2011); há necessidade de metodologias e estratégias na educação de surdos, não se limitando apenas à tradução para a língua de sinais. É preciso intervenção pedagógica por meio de exemplos, materiais e linguagem adequada, como percebeu-se nessa atividade.

No segundo momento desse encontro, propôs-se aos alunos a participação em um jogo denominado "Jogo da batalha no campo de futebol da geometria", uma adaptação do jogo originalmente conhecido como Batalha Naval. De acordo com Grango (2004), a inserção de jogos no ensino de matemática proporciona situações que desafiam os alunos e os motivam a conhecer seus limites, adquirindo confiança e despertando o interesse pela busca da solução (GRANDO, 2004).

O jogo no ensino de matemática apresenta vantagens, como o desenvolvimento de estratégias, a tomada de decisões, a participação ativa dos alunos, desperta o interesse e motivação (GRANDO, 2004). Ainda corroborando Grando (2004), a apresentação das regras deve ser clara para os jogadores, e os acordos comuns devem acontecer antes do início do jogo. Então houve a projeção das as regras na tela de multimídia e realizou-se a intepretação em Libras, porém não foram compreendidas por todos os alunos, então a professora de matemática sugeriu que realizassem algumas jogadas para exemplificar. Isso possibilitou o entendimento das regras pelos alunos, reafirmando a necessidade de tarefas visuais, como explicam Peixoto e Lopes no tocante à matemática na educação de surdos (2016, p. 245): "[...] eficiência do olhar surdo sobre os elementos da matemática reelaborados visualmente e em Libras".

No desenvolvimento da atividade "Jogo da batalha no campo de futebol da geometria", os estudantes formaram grupo de quatro alunos e receberam um kit do material (tabuleiro e as fichas com as formas geométricas). $O$ jogo consiste em distribuir no tabuleiro (formado por um plano cartesiano) as fichas com figuras geométricas, sem que a dupla adversária saiba a posição das figuras. Ao iniciar o jogo, um dos estudantes escolhe uma das coordenadas possíveis do plano cartesiano e expressa ao adversário; se acertar, ganha a figura geométrica do oponente, e se errar, o colega responde "tiro na água" e o jogo continua passando a vez de jogar ao adversário. Vence aquele que conseguir primeiro as fichas do oponente.

Ao iniciar as jogadas, os alunos perceberam que precisavam combinar como seriam sinalizadas as coordenadas do ponto (eixo abscissas e eixo das ordenadas), e após alguns minutos de conversa, concordou-se em usar a mão direita mais acima para o número do eixo horizontal e a mão esquerda mais acima pra o número do eixo vertical, como ilustrado na Figura 3. 
Figura 3: Alunos jogando batalha no campo de futebol da geometria

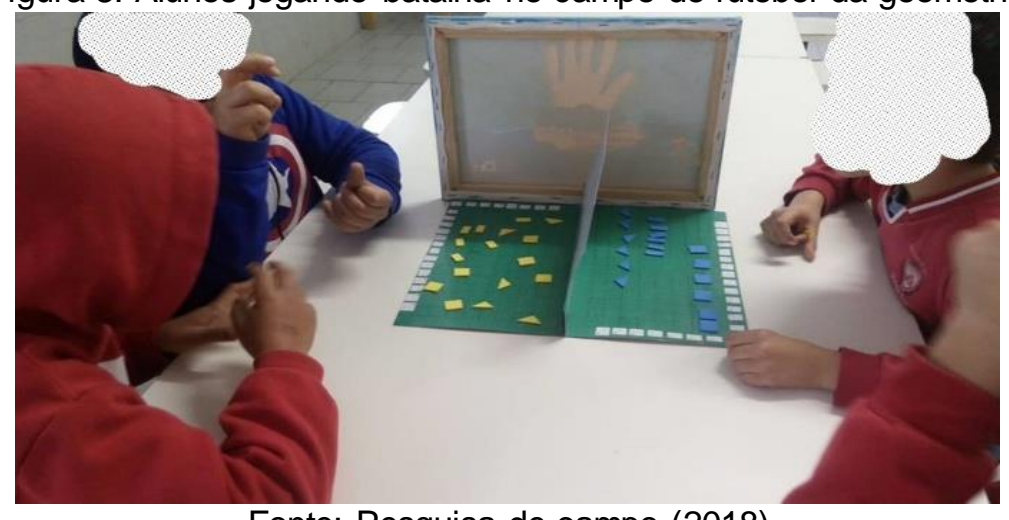

Fonte: Pesquisa de campo (2018)

Os alunos se mostraram muito motivados com a atividade e foi possível observar a compreensão dos conceitos desenvolvidos, uma vez que expressavam as coordenadas do ponto e nominavam as figuras geométricas envolvidas. Para concluir esse encontro, propôs-se uma última tarefa escrita sobre os conhecimentos trabalhados, explicada e interpretada em Libras. Na tarefa, questionou-se quais e quantas eram as figuras geométricas, os nomes e as características de cada uma.

Destacou-se a atividade realizada pelo aluno Aluno 3, cujo enunciado solicitava que fizesse um desenho com as peças (formas geométricas) obtidas no jogo, como reproduzido na Figura 3 , e a seguir o diálogo realizado com a pesquisadora sobre a construção do aluno (Quadro 3).

Figura 3: Desenho do aluno Aluno 3

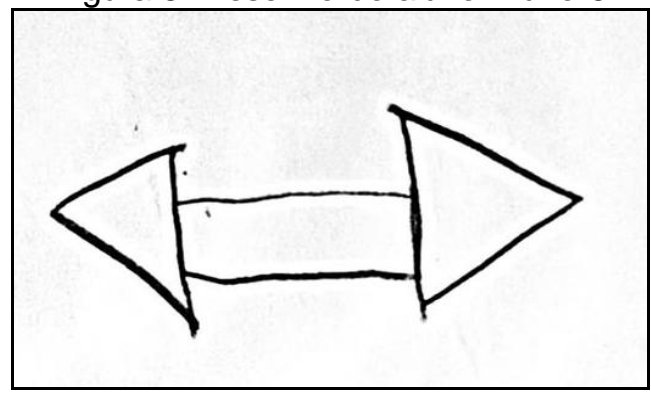

Fonte: Pesquisa de campo (2018)

Quadro 3: Diálogo sobre o desenho do aluno Aluno 3

Pesquisadora: Aluno 3, o que você desenhou?

Aluno 3: Eu desenhei a luz que pisca na van.

Pesquisadora: Não entendi.

Aluno 3: Eu venho para a escola com a van, e o motorista quando dirige e dobra em uma rua à esquerda, eu vejo uma luz piscar no painel, ou quando ele dobra para o outro lado, pisca para direita.

Pesquisadora: Entendi, Aluno 3! Você desenhou a "seta da 
van". Parabéns! Você é muito criativo.

Fonte: Pesquisa de campo (2018)

$\mathrm{Na}$ explicação do aluno Aluno 3, ele usou o movimento do corpo, além dos sinais em Libras, para complementar o diálogo. Nessa tarefa, pode-se observar duas questões importantes no processo de ensino e aprendizagem: a relação com o cotidiano dos alunos e a língua de sinais como facilitadora do conhecimento. Como afirma Vygotski (1997), a educação de surdos está situada nas experiências sociais e na sala de aula e é preciso partir dessas experiências para o ensino e a aprendizagem. $O$ ensino de matemática na educação de surdos deve possibilitar momentos de aprendizagem que envolvam os recursos visuais e o ensino contextualizado, de modo a motivar os alunos e desenvolver sua curiosidade (SOARES; SALES, 2018).

Entre os desenhos com as formas geométricas, outro de destacou, um trem desenhado por Aluno 1 (Figura 4), que quando questionado sobre o que era, sinalizou trem. Mas seu sinal não era conhecido pela pesquisadora, que solicitou que Aluno 1 explicasse novamente, e este encenou como se tivesse puxando a corda que faz o barulho do apito do trem.

Figura 4: Desenho do aluno Aluno 1

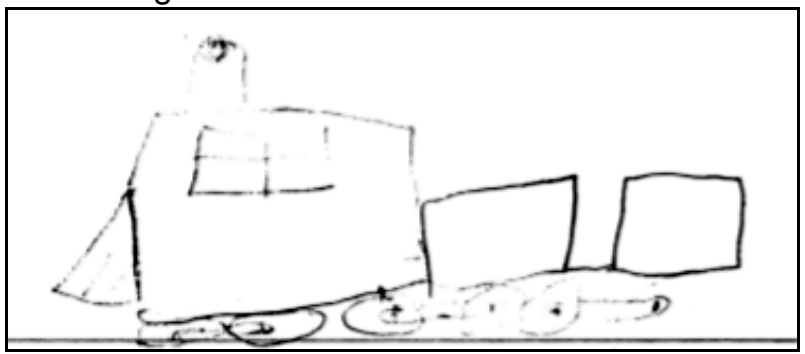

Fonte: Pesquisa de campo (2018)

As atividades permitiram a observação do processo de apropriação dos conhecimentos pelos alunos, assim como a oportunidade de compartilharem conhecimentos mediados por signo, no caso a língua de sinais. De acordo com Vygotski (1997), a escola possibilita a organização das questões que cercam a vida social das crianças surdas, como também o desenvolvimento da língua. Góes (2012) afirma com relação à surdez: "não há limitações cognitivas ou afetivas inerentes à surdez, tudo depende das possibilidades oferecidas pelo grupo social para seu desenvolvimento, em especial para consolidação da linguagem".

O uso de diversos materiais para compreensão dos conceitos geométricos possibilita a exploração dos diferentes aprendizados. Lemos e Kaiber (2018) assinalam que a articulação de materiais diversos potencializa o ensino e aprendizagem dos conhecimentos geométricos, permitindo superar as dualidades dos estudantes com estratégias diferentes.

A experiência desenvolvida nos dois encontros com os alunos surdos mostrou a importância da relação da matemática em um contexto real; as correspondências feitas pelas crianças revelaram que o objetivo da atividade foi efetivado, e inferiu-se que houve apropriação dos conhecimentos. Gesser (2009) assevera que a educação de surdos envolve a questão da oportunidade, o acesso a uma escola com respeito às diferenças linguísticas e com o reconhecimento da cultura surda.

\section{Considerações finais}


Este estudo teve como objetivo realizar um relato de experiência com o uso de estratégias visuais e contextualizadas para o ensino de geometria com crianças surdas em uma escola bilíngue. Destaca-se que as experiências realizadas mostraram o crescimento qualitativo dos conceitos envolvidos, mediados por objetos manipuláveis diversos e a língua de sinais como meio de interação entre os sujeitos envolvidos. Na visão do letramento, em um contexto bilíngue, a Libras como primeira língua e a Língua Portuguesa como segunda língua constituem-se objeto de conhecimento e um caminho para o acesso ao conhecimento matemático (COUTINHO; CARVALHO, 2016).

A constituição de um ambiente de ensino e aprendizagem de matemática na educação de surdos necessita de sensibilização quanto a diversos aspectos, de modo a se considerar a construção do conhecimento por uma matemática visual, como explanam Soares e Sales (2018, p. 86): "o desenho adquire característica potencializadora e representativa da aprendizagem, pelo qual o surdo aproxima imaginação e realidade, conhecimento concreto e subjetivo".

Observou-se nas atividades desenvolvidas pelos alunos a apropriação dos conceitos geométricos desenvolvidos à medida que estes reconheciam as formas e as caraterísticas das figuras geométricas, assim como a localização das coordenadas do ponto no plano cartesiano. Inferiu-se que a diversidade de materiais utilizados, aliada à mediação do conhecimento por meio de instrumentos e da língua de sinais, proporcionou aos estudantes um ambiente rico para a consolidação do processo de ensino e aprendizagem.

Espera-se que este estudo contribua para o desenvolvimento e ampliação das pesquisas no campo da matemática na educação de surdos, necessária e latente para a consolidação do conhecimento.

Agradecimentos

O presente trabalho foi realizado com apoio da Coordenação de Aperfeiçoamento de Pessoal de Nível Superior (CAPES). Gostaríamos de agradecer aos estudantes, professores, coordenação pedagógica e direção da escola de surdos que colaboraram com a atividade realizada.

\section{Referências}

ARNOLDO J. R. H.; RAMOS, M. G.; THOMA, A. S. O uso do multiplano por alunos surdos e o desenvolvimento do pensamento geométrico. Cadernos Cedes, Campinas, v. 33, n. 91, p. 387-409, 2013.

BRASIL. Lei no 10436 de 24 de abril de 2002. Dispõe sobre a Língua Brasileira de Sinais - Libras e dá outras providências. Diário Oficial da União, DF, 25 de abr. 2002.

BRASIL. Decreto ํo 5626 de 22 de dezembro de 2005. Regulamenta a Lei no 10436 de 24 de abril de 2002, que dispõe sobre a Língua Brasileira de Sinais -Libras, e o art. 18 da Lei no 10098, de 19 de dezembro de 2000. Diário Oficial da União, Brasília, DF, 23 de dez. 2005.

BRASIL. Ministério da Educação. Secretaria de Educação Básica. Base Nacional Comum Curricular. Brasília, DF: MEC, 2017. Disponível em: < http://basenacionalcomum.mec.gov.br/>. Acesso em: 24 mai. 2018.

COUTINHO, M. D. M. C.; CARVALHO, D. L. Educação matemática, surdez e letramentos: 
o processo de ensinar e aprender matemática mediado por duas línguas em contato. Revista Paranaense de Educação Matemática, Campo Mourão, v. 5, n. 9, p. 33-55, 2016. Disponível em: http://www.fecilcam.br/revista/index.php/rpem/article/viewFile/1206 /pdf_200. Acesso em: 19 maio 2019.

GESSER, A. LIBRAS? Que língua é essa?: crenças e preconceitos em torno da língua de sinais e da realidade surda. São Paulo: Parábola Editorial, 2009.

GRANDO, R.C. O jogo e a matemática no contexto da sala de aula. São Paulo: Paulus, 2004.

GÓES, M. C. R. de. Linguagem, surdez e educação. 4 ed. Campinas, SP: Autores Associados, 2012.

HEALY, L.; FERREIRA SANTOS, H. Changing perspectives on inclusive mathematics education: Relationships between research and teacher education. Education as Change, v. 18, n. sup1, p. S121-S136, 2014.

KRITZER, K. L.; PAGLIARO, C. M. Matemática: Um desafio internacional para estudantes surdos. Cadernos Cedes, v. 33, n. 91, p. 431-439, 2013.

LACERDA, C. B. F. de.; SANTOS, L. F. dos.,; CAETANO, J. F. Estratégias metodológicas para o ensino de alunos surdos. In: LACERDA, C. B. F. de; SANTOS, L. F. dos. Tenho um aluno surdo e agora? Introdução à LIBRAS e Educação de surdos. São Carlos: EdUFSCar, 2013, p.185-200.

LEMOS, A.V.; KAIBER, C.T. Proposta de estudos de recuperação para a geometria dos anos finais do ensino fundamental. Educação Matemática em Revista - RS, v. 1, n. 19, p. 46-60, 2018. Disponível em: http://sbemrs.org/revista/index.php/2011_1/article/view/ 341/227 Acesso em: 19 mai. 2019.

MOURA, M.C. de. Surdez e linguagem. In: LACERDA, C.B.F. de; SANTOS, L.F. dos (org.) Tenho um aluno surdo, e agora? Introdução à LIBRAS e Educação de surdos. São Carlos: EdUFSCar, 2013, p.13-26.

PEIXOTO, J. L. B.; LOPES, L. S. da F. A videoaula mediando o ensino da matemática para surdos. Revista Paranaense de Educação Matemática, v. 5, n. 9, p. 233-247, 2016. Disponível em: http://www.fecilcam.br/revista/index.php/rpem/article/view/1274. Acesso em: 19 mai. 2019.

SALES, E. R.; PENTEADO, M. G.; MOURA, A. Q. A negociação de sinais em Libras como possibilidade de ensino e de aprendizagem de geometria. Bolema, Rio Claro, v. 29, n. 53, p. 1268-1286, 2015. DOI: http://dx.doi.org/10.1590/1980-4415v29n53a23 Disponível em: http://www.scielo.br/scielo.php?script=sci_arttext\&pid=S0103-636X2015000301268\&lng=p t\&tlng=pt . Acesso em: 16 mai. 2018.

SANTANA, J. E. S.; MUNIZ, S. C.S.; PEIXOTO, J. L. B.Diálogos entre uma Pedaqogia Surda e o Ensino de Matemática. Com a palavra o professor, Vitória da Conquista, v.3, n.2, p.111-131, maio-agosto, 2018. DOI: https://doi.org/10.23864/cpp.v3i2.252. Disponível em: http://revista.geem.mat.br/index.php/CPP/article/view/252. Acesso em: 19 mai. 2019.

SILVA, M.C.A. da. Os surdos e as notações numéricas. Maringá: Eduem, 2010. 
SOARES, M. E.; SALES, E. R. Das memórias às ideias: Orientacõos sobre a visualidade na Educação Matemática para surdos. REPPE - Revista de Produtos Educacionais e Pesquisas em Ensino, Cornélio Procópio, PR, v. 2, n. 1, p. 61-90, 2018. Disponível em: http://seer.uenp.edu.br/index.php/reppe/article/view/1331/671. Acesso em 19 mai. 2019.

VISMARA, L. de S. Os ingredientes para uma Educação de Qualidade: tasa-arvoisuus e oppia ik ä kaikki. In: FIORENTINI, D.; FERNANDES, F. L. P; CARVALHO, D. L. (org.). Narrativas de práticas e de aprendizagem docente em Matemática. São Carlos: Pedro \& João Editores, 2015, p. 177-198.

VYGOTSKI, L. S. Obras escogidas V: Fundamentos de defectologia. 2 ed. Madri: Visor, 1997. 